\title{
Solidariedade e autonomia individual
}

\author{
Alessandro Pinzani \\ alessandro@cfh.ufsc.br \\ Universidade Federal de Santa Catarina / CNPq, Florianópolis, Santa Catarina, \\ Brasil
}

resumo 0 artigo discute o papel da solidariedade na sociedade pós-convencional, mostrando como ela se entrelaça com a noção de uma autonomia individual amparada em direitos fundamentais. Para este fim, serão considerados dois experimentos mentais pensados por Joel Feinberg e Eamonn Callan, em seguida, se passará à definição que Jürgen Habermas e Axel Honneth deram do conceito de solidariedade e, finalmente, serão apresentadas algumas considerações sobre o conceito de autonomia individual.

palavras-chave solidariedade; autonomia; Habermas; Honneth

\section{Dois experimentos mentais}

Nos últimos anos difundiu-se aparentemente um certo descontentamento perante teorias da justiça que se concentram exclusiva ou principalmente em direitos de indivíduos ou grupos. Não se trata de pôr em questão o valor prático e o significado teórico do conceito de direitos individuais ou coletivos; antes, procura-se ampliar a perspectiva a partir da qual podem ser enfrentadas questões de justiça. Considero a teoria do reconhecimento de Axel Honneth como sendo uma expressão deste descontentamento, mas há outros autores que receiam que, ao focalizar os direitos individuais ou coletivos, as questões de justiça acabem sendo reduzidas a questões meramente jurídicas. Os seres humanos possuem esta é a crítica - necessidades que vão além da necessidade de direitos; as teorias convencionais, porém, não dispõem de uma linguagem na qual 


\section{8}

tais necessidades possam ser formuladas como exigências de justiça ou ser entendidas como tais. Isto não significa que qualquer exigência humana possa tornar-se legitimamente objeto de uma exigência de justiça,já que isto significaria abrir uma caixa de Pandora. A idéia é antes a de encontrar um ponto de vista teórico que nos permita ampliar o espectro das exigências de justiça legítimas além das meras pretensões jurídicas, sem por isso ampliar o conceito de justiça a ponto de torná-lo sem sentido prático - isto é, sem abrir a caixa de Pandora.

Não se trata, então, de substituir as tradicionais teorias da justiça, mas de integrá-las por meio de uma maior atenção a experiências ou fenômenos de injustiça que não podem ser descritos apropriadamente na linguagem dos direitos. O debate acerca do reconhecimento - não somente no sentido de Honneth, mas também na versão oferecida por vários teóricos do multiculturalismo - vai parcialmente nesta direção, embora frequentemente prevaleça a dimensão do reconhecimento jurídico. Também o debate acerca de recursos que não podem ser criados ou garantidos juridicamente, como por exemplo a solidariedade, aponta para uma preocupação com aqueles aspectos da vida social que não podem ser objetos de direitos e que contudo são necessários quer para os indivíduos, quer para a sociedade. Tal necessidade pode ficar mais clara se fizermos um experimento mental ou, melhor, se nos servirmos de dois experimentos mentais formulados respectivamente por Joel Feinberg e Eamonn Callan para entender em que sentido uma sociedade justa precisa de solidariedade.

No seu célebre experimento mental, Feinberg imagina "Nowheresville - um mundo muito parecido com o nosso, com exceção do fato de que ninguém ou quase [...] possui direitos", mas cujos habitantes são particularmente virtuosos e cheios de "benevolência, compaixão, simpatia e piedade", virtudes demonstradas na ajuda recíproca que eles prestam uns aos outros "por motivos de mera compaixão" ou até por dever - ainda que a tal dever não corresponda direito nenhum (FEINBERG, 1970, 243). O exemplo de Callan descreve uma situação especularmente contrária: uma democracia que garante a todos os seus cidadãos, além de todos os direitos individuais básicos, amplos direitos sociais; que permite até aos estrangeiros residentes participar no processo decisório; que facilita com medidas de apoio financeiro a atividade política dos cidadãos e que protege juridicamente as minorias. Contudo, seus cidadãos são indivíduos egoístas e 
calculistas, que consideram as instituições como simples meios para alcançar seus fins particulares e que possuem uma atitude fortemente preconceituosa em relação a todos os concidadãos que se diferenciem deles pela cor da pele, pela orientação sexual, pela religião, pela opinião política etc. Além disso, eles veem nos concidadãos meros concorrentes na busca pelas prestações e pelos serviços do Estado (CALLAN, 1997, 1 s.). Se a sociedade descrita por Feinberg se caracteriza pela ausência de direitos e pela relação afetiva de mútua compaixão entre os cidadãos, a descrita por Callan, pelo contrário, se caracteriza por um máximo de direitos individuais e a ausência de laços afetivos entre os cidadãos.

Deixarei de lado a questão de saber em qual destas sociedades preferiríamos viver (ainda que se trate de uma questão interessante e cuja discussão mereceria ser aprofundada ulteriormente) e apontarei, antes, para a conclusão à qual os dois experimentos mentais parecem nos levar. Os dois autores, evidentemente, querem mostrar a unilateralidade da perspectiva a partir da qual cada uma das duas sociedades em questão é construída (a da compaixão mútua e a dos direitos) e consideram fortemente indesejável a ausência de direitos e laços afetivos, respectivamente. A razão que leva os autores a proclamar tal indesejabilidade não é, contudo, exatamente a mesma. Feinberg aponta para o fato de que sem direitos os indivíduos não podem desenvolver "aquele respeito de si mínimo que é necessário para ser digno do amor e da estima dos outros" e que pode ser chamado de "dignidade humana" (FEINBER G, 1970, 250). Callan insiste mais sobre a instabilidade de uma sociedade do tipo por ele descrito: "as instituições da democracia liberal parecem aqui prestes ao colapso porque a moralidade pública compartilhada que um tempo as vivificava desapareceu, e, portanto, elas sobrevivem somente como um sistema de tabus sem sentido ou como um modus vivendi entre grupos antagônicos que as suportarão somente enquanto elas servirem aos seus interesses" (CALLAN, 1997, 2). A preocupação de Feinberg é com o respeito de si dos indivíduos, que ele vincula à existência de instituições como os direitos individuais; a de Callan é com a estabilidade da sociedade democrática, que ele vincula à existência de uma moralidade pública compartilhada. Os dois, contudo, apontam ambos para a necessidade de juntar o aspecto meramente institucional (os direitos) com um aspecto moral ligado à dimensão individual (à compaixão no primeiro 
caso, a uma atitude menos egoísta e mais tolerante no segundo caso). Poderíamos formular de outra maneira a questão e afirmar que, para os dois, uma sociedade não pode ser somente justa, mas deve ser também solidária (no caso de Callan) e vice-versa (no caso de Feinberg). Contudo, as razões para isto parecem ser diferentes: uma sociedade justa, mas não solidária, seria instável; uma solidária, mas não justa, não garantiria a autoestima dos indivíduos.

A estas duas diferentes razões correspondem duas perspectivas a partir das quais podemos observar o fenômeno da solidariedade. A primeira é a perspectiva funcionalista, que vê nele o instrumento que permite a uma sociedade manter-se íntegra. A segunda considera a solidariedade do ponto de vista moral como uma atitude que os indivíduos são obrigados moralmente a assumir em relação aos outros. As duas perspectivas não se excluem reciprocamente, antes podem integrar-se mutuamente e apontam para o caráter peculiar da solidariedade, que pode ser por um lado uma força de integração social e por outro uma atitude moralmente vinculante. Ambas apontam, finalmente, para uma esfera intersubjetiva superior à das relações privadas (da amizade ou do amor, por exemplo) e para uma sociedade vista não como um mero conjunto de indivíduos, mas como uma comunidade - para usar uma dicotomia (aquela entre sociedade e comunidade) um pouco simplista, que, embora remeta a Tönnies, não coincide completamente com a visão deste autor (cf. TÖNNIES, 1887). Segundo Tönnies, enquanto na sociedade os indivíduos agem simplesmente com base em cálculos egoísticos e em busca do seu próprio interesse, na comunidade não somente impera uma vontade comunitária (gemeischaftlicher Wille ou Wesenwille), que lembra a vontade geral de Rousseau no fato de orientar-se pelo interesse comum, mas - além disso - as relações entre os membros são relações afetivas modeladas nas relações familiares. O termo "solidariedade", se aplicado a uma sociedade, me parece apontar para esta dimensão afetiva ou sentimental das relações entre os seus membros e, portanto, para uma visão de tal sociedade nos termos de uma comunidade (ainda que isto não corresponda - repito-o - à posição de Tönnies, para o qual a comunidade só pode ter dimensões territorialmente limitadas, exceto o caso das comunidades religiosas, que, contudo, representam um tipo específico de comunidade). 
Afirmar, portanto, que uma sociedade precisa, além de uma justiça meramente jurídica, dispor sobre o recurso da solidariedade entre seus membros, aponta para uma visão de sociedade diferente (ainda que não alternativa ou contraditória) daquela das teorias tradicionais da justiça. Permanece aberta, contudo, a questão da definição do conceito de solidariedade. Nos dois exemplos acima mencionados, por ex., a atitude dos cidadãos é descrita por Feinberg em termos afetivos recorrendo-se aos conceitos de compaixão, benevolência, simpatia e piedade, enquanto Callan se refere a uma genérica moralidade comum baseada numa atitude que não considere os outros como meros instrumentos ou como obstáculos para a realização dos próprios fins. Poder-se-ia afirmar que somente a primeira atitude merece a denominação de solidariedade, enquanto a segunda se aproximaria mais de uma atitude de respeito da dignidade alheia como a exigida por Kant. Na realidade, esta objeção pressupõe que no conceito de solidariedade esteja implícito um elemento afetivo ou emotivo essencial. Esta visão daria lugar a uma comunidade solidária na qual os vínculos entre os cidadãos são essencialmente vínculos afetivos e, portanto, ela aproximaria a solidariedade à amizade aristotélica. Parece-me, contudo, que é possível defender uma visão de solidariedade diferente, menos ligada à existência de vínculos afetivos diretos entre os cidadãos - uma solidariedade mais racional do que emotiva, por assim dizer, que daria lugar a uma comunidade solidária de outro tipo. Para definir estes dois tipos de solidariedade me servirei das análises que Jürgen Habermas e Axel Honneth dedicaram a este conceito.

\section{Solidariedade e sociedade: Habermas e Honneth}

Em Comentários à ética do discurso Habermas defende uma moral universalista de cunho kantiano (como a própria ética do discurso) das objeções de inspiração hegeliana de Rüdiger Bubner, mas concorda, interessantemente, com uma observação deste autor, segundo a qual só podemos guiar nossas ações com base no imperativo categórico kantiano ou no princípio do discurso porque na nossa sociedade tais princípios são reconhecidos como válidos (HABERMAS, 1991, 33 s.). Habermas reconhece que "cada moral universalista depende de formas da vida 
favoráveis". Estas lhe são favoráveis não somente no sentido de produzir sujeitos que no seu agir se orientam por princípios universais, mas também porque dispõem de práticas e instituições sociais, políticas e jurídicas organizadas na base de tais princípios, as quais permitem, portanto, traduzir deveres morais abstratos em concretas obrigações no nível da vida cotidiana. "Uma moral universalista precisa também de uma certa harmonia com instituições políticas e sociais nas quais representações morais e jurídicas pós-convencionais já estão presentes” (Ib., 25).A perspectiva moral pode destarte ser vista como uma perspectiva ética não no sentido de ser válida somente numa determinada sociedade e com respeito a um determinado conceito de vida boa, mas porque ela pode ser tomada somente se nos encontrarmos numa sociedade que assume tal perspectiva em geral.

Isto leva Habermas a definir a moral como um "dispositivo de segurança" que "compensa uma vulnerabilidade ínsita estruturalmente em formas de vida socioculturais" (Ib., 14). Neste sentido, um papel central é desempenhado por um conceito que chamarei de solidariedade 1. Solidariedade 1 surge pela extrema vulnerabilidade do ser humano. Esta última, por sua vez, não é "a tangível possibilidade da violação da integridade de corpo e vida" (a integridade, então, que para muitos representa o ponto de partida de qualquer concepção moral e de qualquer teoria jurídica), mas diz respeito ao fato de esta "identidade ser como que constitucionalmente ameaçada e cronicamente delicada" (Ib., 15). Tal solidariedade está em relação com o contexto mediado comunicativamente que é necessário para a formação da identidade individual (conforme a teoria de Mead retomada por Habermas) e que constitui uma rede sutil de reconhecimento recíproco.

Este "entrelaçamento vital de relações de reconhecimento recíproco" forma uma rede "de faltas de proteção recíproca e de necessidades de proteção explícitas” - rede que por sua vez necessita de proteção (Ib., 15 s.). O que deve ser protegido não é somente a integridade dos indivíduos, mas também a desta rede: assim como "nenhuma pessoa pode afirmar sua identidade por si só", ninguém pode "afirmar sua integridade por si só. A integridade dos indivíduos exige a estabilização" da rede de relações de reconhecimento recíproco. A exigência de proteção das relações intersubjetivas pelas quais os indivíduos constituem sua identidade corresponde a 
um princípio de solidariedade (no sentido de solidariedade 1). Este último é complementar a um princípio da justiça que por sua vez exige o respeito da dignidade de cada um. "A justiça [...] diz respeito à liberdade subjetiva de indivíduos não representáveis; a solidariedade, pelo contrário, diz respeito ao bem-estar de companheiros fraternizados numa forma de vida intersubjetivamente compartilhada" (Ib., 16) e, portanto, diz respeito à própria forma de vida. A moral não pode proteger "os direitos dos indivíduos sem [proteger] o bem-estar da comunidade à qual eles pertencem”.

Portanto, solidariedade 1 não diz respeito diretamente ao interesse pelo bem-estar de outros, mas ao interesse pela manutenção de uma rede social íntegra. Disto não deriva um princípio moral, mas um princípio que exige a promoção do bem-estar dos outros enquanto companheiros "numa forma de vida intersubjetivamente compartilhada", isto é, a promoção do bem-estar da própria forma de vida e a proteção das relações intersubjetivas; tal princípio não exige, porém, a promoção (nem mesmo a consideração) do bem-estar dos outros enquanto tais. A proteção da integridade da forma de vida leva, então, à proteção da integridade de sujeitos morais; neste sentido, solidariedade 1 tem a ver com a moralidade e não somente com a eticidade; por outro lado, trata-se de um interesse indireto pelo bem-estar dos outros: o que conta é, sobretudo, a manutenção de uma rede social íntegra.

Em Direito e democracia, Habermas introduz um segundo tipo de solidariedade, que chamarei de solidariedade 2 e que não possui um caráter normativo imediato. Trata-se de um conceito socioteórico que Habermas não define diretamente, mas do qual é possível elaborar uma definição a partir de vários passos do texto. Ela consiste num consenso de fundo prévio relativo a valores compartilhados intersubjetivamente pelos quais os atores se orientam e nasce num contexto ético de hábitos, lealdades e confiança recíproca, com base no qual podem ser solucionados os conflitos que surgem em contextos de interação (Habermas fala em "estruturas pretensiosas de reconhecimento recíproco, as quais nós descobrimos nas condições de vida concreta": HABERMAS 1997, I 107). Como força de integração social, a solidariedade 2 é um dos três recursos a partir dos quais "as sociedades modernas satisfazem suas necessidades de integração e de regulação" (Ibidem, II 22). Os outros dois recursos são o dinheiro e o poder administrativo, que são os meios, respectivamente, do sistema da 
economia e do da administração. A oposição entre mundo da vida e sistema, central no pensamento habermasiano, emerge, então, aqui como a oposição entre solidariedade, por um lado, e dinheiro e poder administrativo, por outro. Das três forças de integração social, a solidariedade parece ser a mais fraca. Com efeito, por um lado, os dois sistemas da economia e da administração tendem a colonizar o mundo da vida através dos meios do dinheiro e do poder administrativo. Por outro lado, a crescente complexidade da sociedade e dos processos de racionalização tornam impossível dispor de um potencial solidário sociointegrativo suficiente. Abre-se uma "lacuna de solidariedade" que pode ser preenchida somente pelo direito. Com efeito, em reação ao processo de racionalização característico da modernidade o direito recebe uma dupla função: sua primeira tarefa consiste em opor-se ao processo de colonização do mundo da vida ${ }^{1}$; a segunda tarefa é a de assegurar solidariedade social (ou seja, solidariedade 2) nas sociedades (Ib., I 65). Os contextos de interação nos quais "os conflitos antes eram resolvidos eticamente, na base do costume, da lealdade ou da confiança" são agora juridificados (Ib., I 105). Visto que já não há valores comuns, o consenso não é alcançado por meio deles, mas por meio de procedimentos regulados juridicamente que produzem de forma democrática normas jurídicas. A solidariedade é formalizada numa espécie de lealdade procedimental (isto é, de lealdade para com procedimentos democráticos de produção do direito) que supera a fraqueza motivacional dominante nas modernas sociedades secularizadas, já que "sem a retaguarda de cosmovisões metafisicas ou religiosas imunes à crítica, as orientações práticas só podem ser obtidas, em última instância, através de argumentações” e estas últimas precisam de regras rígidas (Ib., I 132). Mas diferentemente de cosmovisões metafísicas ou religiosas imunes à crítica, as argumentações possuem uma força motivacional muito fraca; por isso, em escritos mais recentes Habermas salienta a importância na sociedade contemporânea da religião como fonte de solidariedade (cf. HABERMAS, 2007 e 2008).

A partir dos dois conceitos de solidariedade introduzidos por Habermas podemos, portanto, formular uma definição que reúne diferentes aspectos. Ela é, em primeiro lugar, uma força de integração social e constitui como tal um recurso fundamental para garantir a estabilidade da sociedade. Tal estabilidade, contudo, não é um fim em si mesmo, mas é 
necessária para garantir a integridade dos indivíduos. Solidariedade $1 \mathrm{e}$ solidariedade 2 acabam fundindo-se uma na outra; a perspectiva funcional e a moral se sobrepõem. Solidariedade não é entendida aqui como uma atitude ligada às emoções ou aos sentimentos dos indivíduos, mas à sua preocupação com a integridade do tecido de relações social. Ela pode ser o resultado até de uma preocupação interessada com a integridade da própria forma de vida, e não necessariamente resultar de uma preocupação com o bem-estar dos outros, como vimos. Um tal ponto de vista "egoísta", contudo, possui uma força motivacional fraca. A esta dificuldade concernente ao lado subjetivo da motivação individual se acrescenta outra de caráter objetivo: a solidariedade é extremamente frágil, por ser constantemente ameaçada pelos meios do dinheiro e do poder administrativo. A solução oferecida por Habermas (o direito preenche a lacuna de solidariedade) aponta para uma possível definição do papel da solidariedade em condições de (1) fraqueza motivacional e de (2) colonização do mundo da vida pelos sistemas da economia e da administração, já que a ação do direito se opõe a este último fenômeno e alivia os indivíduos do peso de encontrar a motivação necessária para assumir uma atitude solidária. A solidariedade se transforma assim em "lealdade procedimental": eu manifesto minha solidariedade para com os concidadãos na medida em que garanto minha lealdade a procedimentos democráticos de produção do direito que visam à integridade da sociedade. Em outras palavras, não preciso cuidar ativamente e em primeira pessoa diretamente do bem-estar dos outros, mas do funcionamento de mecanismos de produção jurídica que garantem tal bem-estar.

Antes de tirar minhas conclusões da posição habermasiana, gostaria compará-la com a de Axel Honneth. Em Luta por reconhecimento, Honneth identifica na solidariedade uma das três formas de reconhecimento fundamentais para a formação de uma identidade individual íntegra (as outras duas são o amor e o direito). Na esteira de Hegel, Honneth constrói uma tríade de formas de relacionamento inter-humano que possui uma estrutura dialética (ainda que o próprio Honneth não chame a atenção para este ponto - talvez para não dar a impressão de ficar numa ótica exclusivamente hegeliana, em vez de usar o modelo hegeliano somente como uma base para uma teoria ancorada nos resultados de pesquisas cientificas empíricas). Em Hegel, os três momentos que 
constituem a eticidade são a família, a sociedade civil e o Estado. Neles os indivíduos entram em diferentes tipos de relações entre si e assumem diferentes atitudes. As relações familiares são de natureza afetiva e imediata, enquanto na sociedade civil os indivíduos se enfrentam como sujeitos isolados e egoístas que veem nos outros meros instrumentos para a satisfação recíproca das carências. É na sociedade civil que as categorias jurídicas abstratas da primeira seção da Filosofia do direito (a seção dedicada ao "Direito abstrato", justamente) se tornam direitos e deveres concretos. No Estado, finalmente, os indivíduos estabelecem entre si relações que não são exclusivamente afetivas, nem meramente jurídicas. Longe de ver nos concidadãos alternativamente ou consangüíneos (irmãos), ou simples meios para satisfazer suas necessidades, o cidadão assume em relação a eles uma atitude que o leva a reconhecer neles os membros de uma comunidade à qual ele também pertence e que compartilha interesses gerais superiores àqueles egoístas dos indivíduos. Por esta razão, ele reconhece também a necessidade não somente de superar seu egoísmo em prol do bem comum, mas de identificar seu interesse pessoal com o da comunidade estatal. Neste sentimento, que Hegel chama de patriotismo, podemos ver uma forma de solidariedade, entendida como uma preocupação com o bem-estar da comunidade que o sujeito forma com os outros - preocupação que vai além do mero cálculo.

Parece-me que na tríade amor-direito-solidariedade descrita por Honneth está presente uma dialética análoga. Se as relações amorosas (que são relações primárias, já que levam à constituição do próprio sujeito e lhe dão autoconfiança) representam o momento do imediato, as relações jurídicas (que atribuem direitos aos indivíduos e lhes dão autorrespeito) consideram os sujeitos como indivíduos isolados, meras pessoas jurídicas detentoras de direitos e deveres, enquanto - finalmente - nas relações comunitárias (que dão aos indivíduos autoestima) a exterioridade das relações jurídicas é suprassumida (termo que Honneth, obviamente, não utiliza) numa relação solidária de cuidado ativo entre os membros da comunidade. Destarte, a solidariedade se apresenta como uma atitude dotada de uma tonalidade emotiva impensável nas relações jurídicas. Vale a pena considerar a passagem central na qual Honneth expõe esta diferença:

Relações dessa espécie podem se chamar "solidárias" porque elas não despertam somente a tolerância [passiva] para com a particularidade 
individual da outra pessoa, mas também o interesse afetivo por essa particularidade: só na medida em que eu cuido ativamente de que suas propriedades, estranhas a mim, possam se desdobrar, os objetivos que nos são comuns passam a ser realizáveis (HONNETH, 2003, 210 s., grifo meu).

A solidariedade se traduz num cuidado ativo direto com o bem-estar alheio - cuidado baseado num interesse afetivo e não meramente racional. Somente desta maneira será possível realizar os objetivos comuns que definem, hegelianamente, a comunidade política (ainda que Honneth não exigisse dos indivíduos que eles fizessem de tais objetivos comuns seus objetivos individuais - e esta é, com certeza, uma importante diferença entre ele e Hegel). Numa sociedade pós-tradicional, o objetivo comum é o de garantir a todos os membros a possibilidade de desdobrar suas qualidades para realizar planos de vida boa cuja determinação, contudo, é operada pelos próprios indivíduos e não pela comunidade, como numa sociedade tradicional. Em tal contexto, afirma Honneth, "o conceito de eticidade refere-se agora ao todo das condições intersubjetivas das quais se pode demonstrar que servem à autorrealização individual na qualidade de pressupostos normativos" (ib., 271 s.). Tais condições devem ser o mais amplas e formais possível para evitar impor aos indivíduos modelos de vida boa que eles não escolheram. Deste ponto de vista, um papel fundamental é desempenhado pelos direitos individuais e, portanto, pelo reconhecimento jurídico. Isto leva Honneth a afirmar que "a questão de saber em que medida a solidariedade tem de entrar no contexto das condições de uma eticidade pós-tradicional não pode ser explicada sem uma referência aos princípios jurídicos" (ib., 278). Permanece aberta, então, a questão de quais são os valores materiais que a solidariedade pós-tradicional deveria tentar realizar e o próprio Honneth se recusa a dar uma resposta a tal questão já que "isso não é mais assunto da teoria, mas sim do futuro das lutas sociais" (ib., 280).

As análises de Habermas e Honneth nos apresentam um conceito de solidariedade típico de uma sociedade pós-tradicional, isto é, de uma sociedade que não dispõe de valores materiais comuns nos quais todos os cidadãos se possam reconhecer e que, portanto, é obrigada a recorrer a princípios jurídicos gerais que permitam a cada membro realizar-se com 
base em valores escolhidos livremente. Neste contexto, a solidariedade parece reduzir-se a uma atitude de cuidado com as condições formais da autorrealização individual, mais do que com o bem-estar dos concidadãos. Honneth menciona um "interesse afetivo" pelos planos de vida particulares dos outros, mas ao final atribui um papel central aos direitos individuais e não deixa claro se a solidariedade exige dos cidadãos apoiar diretamente as tentativas de autorrealização dos concidadãos ou somente apoiar as instituições jurídicas que possibilitam tais tentativas.

Emerge aqui uma complicada relação entre primeira pessoa singular e primeira pessoa plural, entre "eu" e "nós". Normalmente, o conceito de solidariedade é conexo à idéia de uma comunidade cujos membros se identificam em algo comum (uma história, uma cultura, uma religião, uma língua ou até um destino, como na idéia de uma Schicksalgemeinschaft). Na linguagem da solidariedade os verbos se conjugam na primeira pessoa plural, por assim dizer. Ora, Habermas e Honneth chamam nossa atenção para o fato de que nas sociedades pós-convencionais o elemento comum ao redor do qual surge um senso de pertença e de solidariedade é formado pelos princípios jurídicos que garantem aos indivíduos o espaço para formar sua identidade de maneira íntegra e para alcançar sua autorrealização. Isto faz com que em tais sociedades o objeto da solidariedade não seja a comunidade em si, mas seus membros como indivíduos. O "nós" da comunidade solidária se preocupa com o bem-estar de cada membro, não da comunidade como um todo. Portanto, o "nós" cuida dos "eus", e, ao fazer isto, em primeiro lugar, torna ainda mais impossível a volta a uma situação como aquela típica das sociedades convencionais. Nestas o elemento comum não é meramente formal em relação à definição de um plano de vida boa - como no caso da igualdade de direitos -, mas possui um conteúdo material, isto é, oferece aos membros modelos concretos de vida boa. Em segundo lugar, porém, o fato de a solidariedade garantir aos indivíduos espaços sempre mais amplos de autorrealização pode solapar a própria base consensual sobre a qual ela se funda. O risco, em suma, é de tornar os indivíduos tão individualistas a ponto de transformá-los em egoístas desinteressados dos outros. Daí a lacuna de solidariedade que o direito é obrigado a preencher, como no modelo habermasiano. Destarte, parece que nos movimentamos num dilema: a solidariedade entendida como reconheci- 
mento do direito de cada membro da sociedade à autorrealização pode acabar solapando suas bases e ameaçar quer a integridade da sociedade, quer as possibilidades de os indivíduos se autorrealizarem. Seria, contudo, impossível pensar para uma sociedade pós-tradicional outra forma de solidariedade que esta ligada à autonomia individual.

\section{Solidariedade e autonomia}

Eu gostaria de finalizar esta apresentação tentando esboçar uma teoria da autonomia individual que faça justiça às teorias de Habermas e Honneth acima apresentadas e, portanto, à noção de solidariedade por eles desenvolvida, mas que - ao mesmo tempo - tente ir um pouco além de tal noção.

Atribuímos autonomia a um sujeito quando ele é capaz de agir conforme um projeto pessoal de vida boa (projeto que, contudo, pode ser inspirado por modelos pré-existentes) e de considerar a si e a outros sujeitos como capazes de estabelecer relações de direitos e deveres (em outras palavras: quando é capaz de ver a si e aos outros como titulares de direitos e possuidores de deveres). Esta definição se refere àquele que podemos chamar de grau mínimo de autonomia, já que esta última é uma qualidade que pode ser possuída de forma maior ou menor: a autonomia de um sujeito se torna maior (1) quanto mais ele constrói seu projeto de vida boa de forma independente dos modelos fornecidos pelo seu ambiente mais próximo (a família, o âmbito social mais restrito, sua cultura etc.) e (2) quanto mais ele atribui (a si e aos outros) direitos e deveres com base em princípios universais e não locais ou sociais. Enquanto no caso (1) uma maior autonomia é relevante somente para o próprio sujeito, já que se trata de ampliar as possibilidades de vida boa dele (este conceito pode ser aproximado ao de capabilidades usado por Amartya Sen e - num sentido um pouco diferente - por Martha Nussbaum), no caso (2) ela se torna relevante para os outros também. Assim, um indivíduo capaz de imaginar para si modelos de vida condenados pelo seu ambiente social mais próximo (por ex. uma mulher proveniente de uma família tradicional e machista que resolva viver sozinha, à custa de transferir-se para outra cidade) aumenta suas chances de viver uma vida 
boa; um indivíduo que passe a considerar outros indivíduos de maneira diferente daquela em que o seu ambiente os considera e lhes atribua mais direitos (por exemplo um irmão da mulher acima mencionada que passe a considerar moralmente legítima uma escolha de vida como a da irmã e atribua às mulheres direitos que os outros membros da sua família ainda lhes denegam com base em suas visões machistas), contribui para criar um ambiente mais favorável a estes outros indivíduos e aos seus planos de vida. Deste ponto de vista, o desenvolvimento de uma maior autonomia neste segundo sentido poderia até ser considerado objeto de uma obrigação moral seja por parte do próprio indivíduo, seja por parte das instituições sociais e políticas. Naturalmente, as próprias instituições representam na maioria das vezes o principal obstáculo para o desenvolvimento deste segundo tipo de autonomia nos sujeitos e, às vezes, até do primeiro tipo de autonomia: famílias, clãs, comunidades religiosas, igrejas, castas, grupos políticos antiliberais, etc. oferecem ao indivíduo elementos fundamentais de orientação moral fornecendo valores e modelos, mas frequentemente o prendem numa visão rígida e restrita do mundo e das categorias morais de lícito e de ilícito. ${ }^{2}$

Um ulterior obstáculo ao desenvolvimento da autonomia é representado pela falta de bens primários no sentido rawlsiano, e primariamente de bens materiais essenciais para a sobrevivência física do sujeito e para uma vida minimamente saudável: uma alimentação variada, uma moradia digna e assistência sanitária básica gratuita fazem parte destes bens materiais essenciais. Deste ponto de vista, podemos recorrer a uma consideração feita por Martha Nussbaum. Na opinião de Nussbaum, uma "sociedade decente" deveria garantir a dignidade dos seus membros não somente de forma negativa, omitindo ações diretamente humilhantes, mas também de forma positiva. Ela deveria criar um "ambiente" que possibilitasse o desenvolvimento do respeito de si (NUSSBAUM, 2004, 282). Nussbaum apresenta o exemplo da miséria, que em muitas sociedades é considerada uma situação humilhante. Isto leva frequentemente à condenação moral dos próprios pobres, como se eles fossem responsáveis pela sua situação - por falta de vontade, por preguiça, por corrupção moral etc. Nussbaum é da opinião de que uma sociedade decente deveria equipar seus membros com um conjunto mínimo de capabilidades (que ela define como as condições - internas, psicológicas ou 
externas, ambientais - que permitem aos indivíduos escolher livremente entre diferentes opções de vida). ${ }^{3}$ Em particular, a filósofa salienta uma delas, que remete à teoria do reconhecimento de Honneth: cada indivíduo deveria possuir "as bases sociais do respeito de si e da não-humilhação a ponto de ser tratado como um ser digno, cujo valor é igual ao dos outros" (ib., 283). Já que um tal conjunto de capabilidades possui uma base econômica, esta última deveria ser garantida institucionalmente, quando não haja a possibilidade de satisfazer de outra forma as exigências básicas dos indivíduos. Medidas como a concessão de ajudas econômicas, a introdução de uma renda básica mínima ou a implementação de programas governamentais como, por exemplo, o Bolsa-Família brasileiro, deveriam ser vistos como tentativas de ajudar os indivíduos a desenvolver suas capabilidades quando eles não disponham de outras possibilidades para fazer isso autonomamente. Ao mesmo tempo, tais medidas representam tentativas de ajudar estes indivíduos a sair de uma situação humilhante como a pobreza extrema.

A partir destas considerações cabe a pergunta se a solidariedade própria das sociedades pós-convencionais, que se preocupa primeiramente com as condições formais (jurídicas) da autonomia individual (entendida como capacidade de desenvolver uma identidade íntegra e como autorrealização) não deveria ser estendida para as condições materiais mínimas de tal autonomia. Em outras palavras: os membros de uma comunidade deveriam ocupar-se de garantir (num nível mínimo) o exercício concreto da autonomia de cada um deles e não simplesmente permitir um exercício meramente teórico ou formal de tal autonomia. A questão é se isto implica num simples dever de ajudar diretamente os concidadãos.

Se respondermos positivamente a tal pergunta, parece-me que nos movimentaremos na direção de uma situação parecida com aquela do experimento mental de Feinberg, já que as possibilidades concretas que cada membro teria de desenvolver sua autonomia dependeriam em última análise da solidariedade imediata dos outros e não seriam objetos de direitos independentes da boa vontade dos concidadãos. Sugiro, portanto, que a solidariedade em questão seja entendida de maneira a implicar um dever de ajuda indireto: os cidadãos se limitariam a criar e sustentar instituições que ofereçam aos indivíduos a possibilidade concreta de desenvolver sua autonomia. Isto, contudo, não evitaria o risco de cair 
numa situação análoga àquela descrita por Callan (no pior dos casos) ou no dilema acima mencionado da solidariedade que solapa sua própria base. Para fugir a tal risco seria necessário, porém, desenvolver um tipo de solidariedade mais "densa", ligada a valores e visões da vida boa compartilhados por todos - uma solidariedade impossível de ser alcançada numa sociedade pós-convencional, como já disse. Por isso, a melhor solução (ainda que se trate de um "sucedâneo", para usar uma expressão kantiana) é traduzir a solidariedade do nosso modelo (e do modelo habermasiano e honnethiano) em instituições as mais estáveis possível e subtraídas ao arbítrio de maiorias volúveis e potencialmente tirânicas. Isto pode implicar a constitucionalização de direitos ligados às condições mínimas para uma vida autônoma (por exemplo do direito a uma renda mínima básica), mas neste ponto devemos concordar com Honneth e deixar que cada comunidade política resolva este tipo de questão com base nos êxitos dos debates e das lutas sociais que sua cultura política e pública tornar possíveis.

1 "Os meios de regulação - dinheiro e poder administrativo - são ancorados no mundo da vida através da institucionalização jurídica dos mercados e das organizações burocráticas" (HABERMAS 1997, I 104 s.). Sob tais premissas, o direito "detém uma função de charneira entre sistema e mundo da vida" (Ib., I 82) e se torna "uma correia de transmissão abstrata e obrigatória através da qual é possível passar solidariedade para as condições anônimas e sistematicamente mediadas de uma sociedade complexa” (Ib., I 107).

${ }^{2}$ Caberia, neste sentido, falar do peso da cultura e do ambiente social, em particular sobre as mulheres, mas não farei isso neste contexto.

3 Estou consciente de que esta é uma definição simplificada do conceito de capability assim como Nussbaum o usa, mas acho que neste contexto ele é suficiente. Não entrarei na questão se é preferível a definição de capability oferecida por ela ou aquela desenvolvida por Sen (que, pessoalmente, considero mais interessante).

\section{Referências bibliográficas}

CALlAN, E. 1997. Creating Citizens. Political Education and Liberal Democracy. Oxford: Oxford University Press. 
FEINBER G, J. 1970. “The Nature and Value of Rights”. In The Journal of Value Inquiry. 4/4, p. 243-257.

HABERMAS, J. 1991. Erläuterungen zur Diskursethik. Frankfurt a. M.: Suhrkamp.

1997. Direito e democracia: entre faticidade e validade. Trad. F. B. Siebeneichler. Rio de Janeiro: Tempo Brasileiro. 2 vols.

. 2007. Entre naturalismo e religião: estudos filosóficos. Trad. F. B. Siebeneichler. Rio de Janeiro:Tempo Brasileiro.

2008. "Ein Bewußtsein von dem, was fehlt / Eine Replik". In REDER, M., e SCHMIDT, J., orgs., Ein Bewußtsein von dem, was fehlt. Eine Diskussion mit Jürgen Habermas. Frankfurt a. M.: Suhrkamp, p. 26-36 e 94-107.

HONNETH, A. 2003. Luta por reconhecimento. A gramática moral dos conflitos sociais. Trad. L. Repa. São Paulo: Editora 34.

NUSSBAUM, M. 2004. Hiding from Humanity. Disgust, Shame, and the Law. Princeton: Princeton University Press.

TÖNNIES, F. 1887. Gemeinschaft und Gesellschaft. Leipzig: Reislad. 